\title{
Irrigation Scheduling using WSN
}

\author{
Mamoun Hussein Mamoun \\ Mansoura University, Faculty of Computer and \\ Information Sciences
}

\author{
Said A. Shokry \\ Mansoura University, Faculty of Computer and \\ Information Sciences
}

\begin{abstract}
Irrigation scheduling is a planning and decision making process, the primary decision being: how much water to apply and when to apply it. Agricultural field figures can be obtained either by direct measurements with sensors placed close to the soil, or by remote sensing with sensors placed in aircrafts or satellites. In remote sensing data are obtained from the electromagnetic wave reflected by soil and vegetation, especially in the bands of visible light, infra-red and microwaves. Microwaves reflection and absorption are strongly affected by soil and vegetation water content, making it possible to estimate these characteristics with the help of radiometric sensors. However, conducting the measurements at land level is advantageous over remote sensing, since it is not affected neither by weather nor field surface conditions. Besides, larger amount of data with better resolution in space and time can be obtained at land level if a large number of special purpose sensors is used. This paper proposes a newly method based on direct measurements using wireless sensor network (WSN) to map the vegetation water content in order to estimate the soil moisture in agricultural fields in coincident with RADARSAT-2 multipolarized information The soil moisture is evaluated over six wheat fields. Results show that, the relative error in retrieving the soil moisture can be degraded through direct measurements by using WSN.
\end{abstract}

\section{General Terms}

Distributed Measurement, Radio Wave attenuation, Vegetation Water Content, Soil Moisture Retrieval, Wireless Sensor Network Application

\section{Keywords}

Wireless Sensor Network, Distributed Measurement, Remote Sensing, Vegetation Water Content, Soil Moisture

\section{INTRODUCTION}

A Wireless Sensor Network (WSN) is a distributed measurement system with applications in many areas: military, commercial, scientific (environmental monitoring), industrial, agricultural and others [1]. This system is composed by a great number of autonomous devices, which communicate to each other in a non guided mode (normally by radios) forming a network. These devices, denominated sensor nodes, execute measurements in the environment and transmit the collected data via the network to an access point connected to a computer, which serves as a data base. Sensor nodes are equipped with memory and processing units and are battery powered. WSN protocols and the sensor node operation mode are oriented to energy efficiency, so that they can operate for periods over a year without human intervention.

WSN is an interesting tool which can be used in crop fields for precision agriculture or precision farming processes. Precision farming processes is a management method for large agricultural fields which considers the specific needs of each particular place inside the field [2]. Traditional management techniques that apply uniform treatment are not adequate for large crop fields because their characteristics change in time and space [3]. Soil attributes (moisture, quantity of nutrients, etc), plant diseases and productivity vary a lot from one area to another on one and the same field [4]. In order to carry out this management process, it is necessary to measure soil, plant and air variables in various spots on the field [5]. Agricultural field figures can be obtained either by direct measurements with sensors placed close to the soil, or by remote sensing with sensors placed in aircrafts or satellites [6]. In remote sensing data are obtained from the electromagnetic wave reflected by soil and vegetation, especially in the bands of visible light, infra-red and microwaves [7]. Microwaves' reflection and absorption are strongly affected by soil and vegetation water content, making it possible to estimate these characteristics with the help of radiometric sensors. However, conducting the measurements at land level is advantageous over remote sensing, since it is not affected neither by weather nor field surface conditions [8]. Besides, larger amount of data with better resolution in space and time can be obtained at land level if a large number of special purpose sensors is used. Different environmental variables are measured with sensors placed in the field and are transmitted by a wireless sensor network to a central computer, even at night. The collected data are then used in decision making processes for the field management.

Irrigation scheduling is a planning and decision making process, the primary decision being: how much water to apply and when to apply it. How much water to apply depends on the soil's available moisture storage capacity and the amount of available water depleted from the soil profile by crop water use. When to apply irrigation water depends on rate of water use by the crop and the total available soil moisture.

This paper presents a newly method for irrigation used the ground wireless sensor network in order to map the vegetation water content for soil moister estimation. The estimated value of the soil moisture can be applied to soil moisture irrigation controller which either allow or bypass scheduled irrigation cycles for irrigation process. This paper is organized as follows. Section 2 describes how a WSN can be used to map vegetation water content in a corn fields. A database used to estimate the soil moisture is presented in section 3. A methodology for the measurements process is described in section 4. Section 5 presents some experimental results obtained from measurements in agriculture fields, which confirm the proposed method. Conclusions are presented in section 6 .

\section{WSN AS A MEASURING TOOL}

A WSN works to measure and transmit data related to agricultural variables, acting as an element of the precision agriculture process, radio signals passing through vegetation will be measured in all sensor nodes to estimate plant water content which is important in the control of growing process.

To estimate plant water content in the field, there is no need to collect plant samples and without the use of an additional specific sensor connected to the wireless sensor network. This 
estimation process is based on the received signal strength information available in the radios of all sensor nodes. This method is different from traditional remote sensing because a distributed measurement system and low cost radios with non directional antennas are used.

A WSN acting as a distributed measurement system can be used to capture data from many areas all over the crop field. The average value obtained by several measurements made by a group of sensor nodes occupying a specific area in the field is considered useful information about the vegetation present in that area. The detection of less water in one area of the field compared to the others can be used to indicate that some problem exists in the soil-plant system in that area. The periodic measurement of the vegetation water content can be used to estimate variations in plant hydric potential during day and night. Distributed measurement of plant water content provides more representative values for agriculturists working with precision-farming than values obtained from a single measurement in one spot, even if taken by more accurate equipment.

\section{DATABASE}

\subsection{Study area}

The study area is a relatively at agricultural region located south of Saskatoon, Saskatchewan, Canada. Over this area, 6 fields of wheat were selected to conduct ground measurements of soil and vegetation characteristics [9].

\subsection{Field data}

Field data based on ground measurements data and on RADARSAT-2 multipolarized information [ 9 ] for 6 selected fields.

\subsection{Ground observation}

Coincident with the RADARSAT-2 satellite overpasses, field campaign measurements of soil surface roughness and crop height were conducted over the wheat fields. Soil surface roughness was measured with a $3-\mathrm{m}$ profile of a pin meter. For each field, the roughness is computed by averaging the roughness parameters (the standard height and the correlation length) obtained from three measurement points sparsely distributed.

The water content of wheat was determined by using wireless sensors nodes disposed in triangular shape distributed in crop fields for measuring the received signal strength (RSS) at all communication paths to calculate the vegetation water content. The WSN used was composed by MICA2 [10] sensor node platforms, with transmitters adjusted to $0 \mathrm{dBm}(1$ $\mathrm{mW}$ ). These sensor nodes employ radios CC1000 [11], which operate in $916 \mathrm{MHz}$ ISM (license free) band. It was taken the measurements of RSS at all communication paths, for all pair of nodes. CC1000 measures and informs received power strength as Received Signal Strength Information, which is an analog voltage ( $V_{R S S I}$ ) related to received power as:

$$
P_{R}=-50 \cdot V_{R S S I}-45.5
$$

$V_{R S S I}$ is converted for a binary value by a 10 bit ADC present in the microcontroller Atmega 128L [12], which is a component of MICA2. The binary indication of RSSI is related to VRSSI as

$$
V_{R S S I}=\frac{R S S I_{D I G} \cdot V_{B A T}}{1024}
$$

where $R S S I_{D I G}$ is the 10 bit binary correspondent to $V_{R S S I}$ and $V_{B A T}$ is the node battery voltage (about $3.0 \mathrm{~V})$.

The absorption factor $\alpha$ obtained when comparing the received power $P_{R}$ into two different conditions, with $\left(P_{R v}\right)$ and without vegetation ( $P_{R f}$...Free condition) [13]

$$
\frac{P_{R v}}{P_{R f}}=e^{-2 \alpha d}
$$

Equation (3), can be written in $\mathrm{dBm}$ as

$$
P_{R f}-P_{R v}=\rho=4.34 \cdot 2 \cdot \alpha \cdot d
$$

Where $\rho$ is the pass loss in $\mathrm{db}$.

It can be shown [14] that the attenuation on microwaves that pass through vegetation is a decreasing exponential function calculated with a product of two terms: a parameter b, that depends on vegetation species, and the vegetation water content (VWC).

$$
\frac{P_{R v}}{P_{R f}}=e^{-b v W C}
$$

The value of parameter $b$ is almost constant. The average values of $b$ is 0.35 for wheat canopies. From equation (3) and equation (5), it can be easily to prove that

$$
V W C=\frac{2 \cdot \alpha \cdot}{b} \quad\left(\mathrm{~kg} / \mathrm{m}^{2}\right)
$$

\section{METHODOLOGY}

The soil moisture estimation over agricultural fields method is based on the combination of semi-empirical backscattering models of soil and vegetation with empirical relationships derived from RADARSAT-2 multi-polarization data.

Over bare soil surfaces characterized by random roughness, the backscattering coefficient $\left(\sigma_{p q, t o t}^{0}\right)$ can be expressed as [9]

$$
\sigma_{p q}^{0}=\frac{A \cos (\theta)}{2 b V W C} h\left(1-e^{-2 b V W C \sec \theta}\right)+\sigma_{p q s}^{0} e^{-2 b V W C s w c \theta}
$$

Where A represents the vegetation scattering $\left(\sigma_{p q v}^{0}\right), \mathrm{h}$ related to crop height, $\mathrm{b}$ is an empirical parameter $(\mathrm{b}=0.35$ for wheat), $\theta$ is the incident angle $\left(10^{\circ}<\theta<70^{\circ}\right)$ and $\sigma_{p q s}^{0}$ represents the soil scattering coefficient given by

$$
\sigma_{p q s}^{0}=0.11 M s^{0.7}(\cos \theta)^{2.2}\left[1-\exp \left(-0.32(k s)^{1.8}\right)\right]
$$

Where $\mathrm{k}$ is the wave number, $\mathrm{s}$ is the rms height of soil surface roughness, Ms is the soil moisture.

Once VWC measured by WSN (as illustrated in the previous paragraph), $\sigma_{p q, t o t}^{0}$ can be retrieved $[9,15]$. Using $\sigma_{p q s}^{0}$ in order to determine the soil moisture. The soil moisture can be applied to soil moisture irrigation controller which either 
allow or bypass scheduled irrigation cycles for irrigation process.

\section{RERSULTS AND DICUSSION}

Table 1 summarized the VWC for the agriculture fields measured by WSN for node displacement $\mathrm{d}=10[\mathrm{~m}]$.

Table 1. Field measurements of $\mathrm{VWC}$ for $\mathrm{b}=\mathbf{0 . 3 5}$

\begin{tabular}{|c|c|c|c|}
\hline Crop type & $\begin{array}{c}\text { No. of } \\
\text { fields }\end{array}$ & $\begin{array}{c}\text { Measured Pass } \\
\text { Loss } \rho[\mathrm{db}]\end{array}$ & $\begin{array}{c}\text { Calculated } \\
\text { VWC } \\
{\left[\mathrm{kg} / \mathrm{m}^{2}\right]}\end{array}$ \\
\hline Wheat & 6 & $22.785-50.127$ & $1.5-3.3$ \\
\hline
\end{tabular}

The collected data from the RADARSAT-2 images are illustrated in Table 2.

Table 2: Summary of the collected field measurements

\begin{tabular}{|c|c|c|c|}
\hline $\begin{array}{c}\text { Crop } \\
\text { type }\end{array}$ & $\begin{array}{c}\text { No. of } \\
\text { fields }\end{array}$ & $\begin{array}{c}\text { Range of s } \\
{[\mathrm{cm}]}\end{array}$ & $\begin{array}{c}\text { Range of crop } \\
\text { height }[\mathrm{cm}]\end{array}$ \\
\hline Wheat & 6 & $1.48-2$ & $33-87$ \\
\hline
\end{tabular}

The average vegetation water content and corresponding soil moisture were calculated and plotted as shown in the following figure

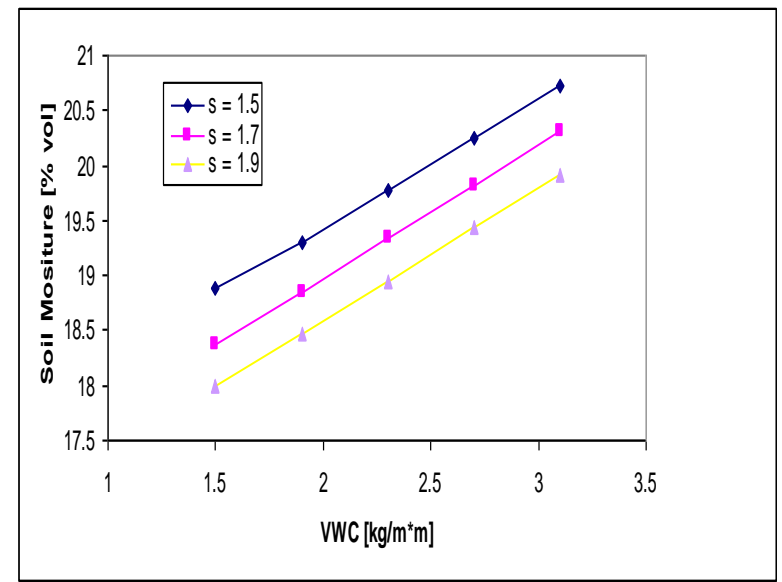

Figure 1: The relation between VWC and Soil Moisture.

From Figure 1, it can be observed that the soil moisture increases when the VWC increases. Furthermore, it is observed that as the rms height of soil surface roughness increases the soil moisture decreases.

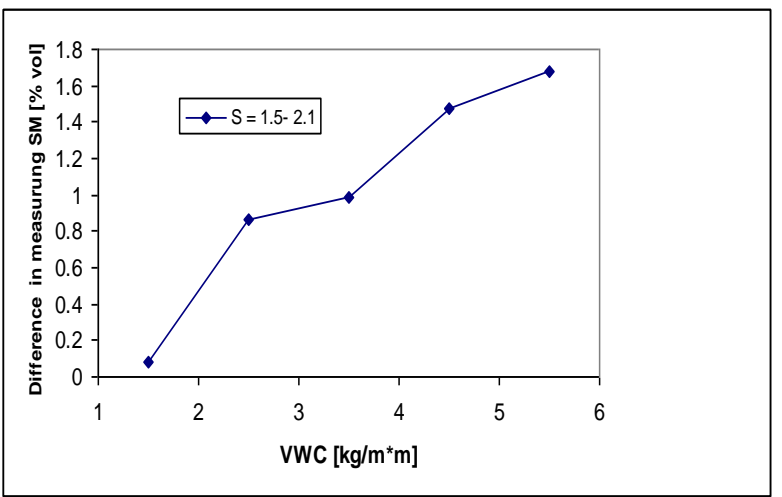

Figure 2: Difference in measuring Soil Moisture versus VWC
From Figure 2, it can be observed that difference in the soil moisture increases when the VWC increases.

Moreover, it is observed from Figure 1 and 2 that, the relative error in retrieving the soil moisture can be degraded.

The estimated soil moisture can be applied in smart irrigation system to soil moisture irrigation controller (acts as a switch) which either allow or bypass scheduled irrigation cycles for irrigation process.

\section{CONCLUSION}

As the demand for water increases, along with the need to protect aquatic habitats, water conservation practices for irrigation need to be effective and affordable. Precision irrigation will optimize irrigation by minimizing the waste of water, and energy, while maximizing crop yields. The most effective method for determining the water demands of crops is the based on the real time monitoring of soil moisture. This paper proposes a newly method based on direct measurements using WSN to map the vegetation water content in order to estimate the soil moisture in agricultural fields in coincident with RADARSAT-2 multipolarized information. Results show that, the relative error in retrieving the soil moisture can be degraded.

The estimated soil moisture can be applied to soil moisture irrigation controller which either allow or bypass scheduled irrigation cycles to on the irrigation timer.

\section{REFERENCES}

[1] Heidemann, J. \& Govindan, R. Embedded Sensor Networks. In Handbook of Networked and Embedded Control Systems. D. Hristu-Varsakelis and W.S. Levine, editors. Springer Verlag, 18p., 2004.

[2] Magri, A. Van Es, H. M, Glos, M. A. and Cox, W. J. "Soil Test, Aerial Image and Yield Data as Inputs for Site-specific Fertility and Hybrid Management Under Revista Maize. Precision Agriculture", Springer Science. pp. 87- 110, 2005

[3] National Research Council - Committee On Assessing Crop Yield: Site-specific Farming. Precision Agriculture In The 21st Century: Geospatial And Information Technologies In Crop Management. National Academy Press, Washington, USA. 149p., 1997.

[4] Mallarino, A. P. \& Wittry D. J. "Efficacy of Grid and Zone Soil Sampling Approaches for Site-Specific Assessment of Phosphorus, Potassium, $\mathrm{pH}$, and Organic Matter", Precision Agriculture, Kluwer Academic Publishers, Netherlands, vol. 5, pp. 131-144, 2004.

[5] Hatfield, J. L. Precision Agriculture and Environmental Quality: Challenges for Research and Educational Agricultural Research Service, USDA, Ames, Iowa. Obtained http://www.arborday.org/PROGRAMS/papers/Precision Ag.html..

[6] Leon, C. T., Shaw, D. R., Cox, M. S., Abshire, M. J., Ward, B., Ward law III, M. C. and Watson, C. "Utility of Remote Sensing in Predicting Crop and Soil Characteristics", Precision Agriculture, Kluwer Academic Publishers, vol. 4, pp. 359-384, 2003.

[7] Hornbuckle, B. K. Radiometric Sensitivity to Soil Moisture Relative to Vegetation Canopy Anisotropy, Canopy Temperature, and Canopy Water Content at 1.4 
$\mathrm{GHz} ; \mathrm{PhD}$ tesis on Electrical Engineering and Atmospheric, Oceanic \& Space Sciences. University of Michgan, 135 p., 2003.

[8] Adamchuk, V. I., Hummel, J. W., Morgan, M. T., Upadhyaya, S. K. "On-the-go soil sensors for precision agriculture", Computers and Electronics in Agriculture, vol. 44, pp. 71-91, 2004

[9] Gherboudj I.., Magagi R., Berg A., Toth B., Aaron A., "soil moisture retrieval over agricultural fields from multi-polarized and multi-angular RADARSAT-2 SAR data", REMOTE Sensing of Environment vol. 115, pp. 33-43, 2011.

[10] Gross bow Technology. Inc(2005). Wireless Sensor Networks. Manual do fabricante, 30p. Disponível em: http://www.xbow.com.

[11] Chipcon AS. CC1000-MSingle Chip 'Very Low Power RF Transceiver (rev. 2.1). Manual do fabricante, pp. 48, Disponivel em: http://www.chipcon.com.

[12] Atmel Corporation. Atmega128L - 8-bit AVR Microcontroller with $128 \mathrm{~K}$ Bytes - In-System
Programmable Flash. Manual do fabricante, 328 p. Disponível: em http://www.atmel.com.

[13] Carlos J., Henrique F., Jose E., "Estimating Vegetation Water Content with Wireless Sensor Communication Signals", Instrumentation and Measurement Technology Conference, IMTC 2007

[14] Wigneron, J-P., Pardé, M., Waldteufel, P., Chanzy, A., Kerr, Y., Schmidl, S. and Skou, N. "Characterizing the Dependence of Vegetation Model Parameters on Crop Structure, Incidence Angle, and Polarization at L-Band", IEEE Transactions on Geoscience and Remote Sensing, vol. 42, pp.416-424, 2004

[15] Khabazan S., Motagh M., Hosseini M., "Evaluation of Radar Backscattering Models IEM, OH, and Dubois using L and C-Bands SAR Data over different vegetation canopy covers and soil depths", International Archives of the Photogrammetry, Remote Sensing and Spatial Information Sciences, Volume XL-1/W3, SMPR 2013, pp. 225-230, October, 2013 